\title{
In vitro antioxidant activity of Vetiveria zizanioides root extract
}

\author{
V. SUBHADRADEVI", K. ASOKKUMAR, M. UMAMAHESWARI, A.T. SIVASHANMUGAM \\ and R. SANKARANAND \\ Department of Pharmacology, College of Pharmacy, Sri Ramakrishna Institute of Paramedical Sciences, \\ Coimbatore, Tamil Nadu, India
}

\begin{abstract}
Free radicals induce numerous diseases by lipid peroxidation and DNA damage. It has been reported that some of the extracts from plants possess antioxidant properties capable of scavenging free radicals in vivo. Vetiveria zizanioides belonging to the family Gramineae, is a densely tufted grass which is widely used as a traditional plant for aromatherapy, to relieve stress, anxiety, nervous tension and insomnia. In this regard, the roots of $V$. zizanioides was extracted with ethanol and used for the evaluation of various in vitro antioxidant activities such as reducing power ability, superoxide anion radical scavenging activity, deoxyribose degradation assay, total antioxidant capacity, total phenolics and total flavonoid composition. The various antioxidant activities were compared with suitable antioxidants such as butyl hydroxy toluene, ascorbic acid, quercetin, alpha tocopherol, pyrocatechol and curcumin respectively. The generation of free radicals $\mathrm{O}_{2-}, \mathrm{H}_{2} \mathrm{O}_{2}, \mathrm{OH}$ and $\mathrm{NO}$ were effectively scavenged by the ethanolic extract of V.zizanioides. In all these methods, the extract showed strong antioxidant activity in a dose dependent manner. The results obtained in the present study clearly indicates that $V$. zizanioides scavenges free radicals, ameliorating damage imposed by oxidative stress in different disease conditions and serve as a potential source of natural antioxidant. The study provides a proof for the ethnomedical claims and reported biological activities. The plant has, therefore, very good therapeutic and antioxidant potential.
\end{abstract}

Keywords: Free radicals, antioxidant, traditional, Vetiveria zizanioides

\section{Introduction}

Free radicals contain one or more unpaired electrons, produced in normal or pathological cell metabolism. Reactive oxygen species (ROS) react easily with these free radicals to become radicals themselves. ROS are various forms of activated oxygen, which include free radicals such as superoxide anion radicals $\left(\mathrm{O}_{2}{ }^{-}\right)$and hydroxyl radicals $(\mathrm{OH}+)$, as well as nonfree radical species $\left(\mathrm{H}_{2} \mathrm{O}_{2}\right)$ and the singled oxygen $\left(\mathrm{O}_{2}\right)(\mathrm{Gulcin}$ et al., 2004). They are formed in living organisms in different ways, including normal aerobic respiration, stimulated polymorphonuclear leukocytes and macrophages, and peroxisomes. They are natural byproducts of our body's metabolism. They are dangerous; however, when present in excess, they can attack biological molecules such as lipids, proteins, enzymes, DNA and RNA, leading to cell or tissue injury (Amarowicz et al., 2004). The cells experience an oxidative stress which contributes in various clinical disorders such as cancer, heart diseases, neurogenerative diseases like multiple sclerosis, Parkinson`s disease, autoimmune disease, stroke, arthritis, ischemia, reperfusion injury, acute hypertension, haemorrhagic shock, emphysema, cirrhosis, diabetes mellitus, hepatitis, cancer, atherosclerosis as well as other ailments (Roome et al., 2008; Ajith et al., 2002; Gomes et al., 2001; Kang et al., 2003).

Great number substances of plant origin have been shown to exhibit antioxidant activity (Ali et al., 2007; Gulcin et al., 2003). The use of antioxidants that scavenge ROS has been studied by evaluating its potential and therapeutic applications. The most commonly

\footnotetext{
*Correspondence: V. SubhadraDevi; E-mail: subhaakshay@gmail.com
} 
used antioxidants since the starting of this century are butylated hydroxyanisole (BHA), butylated hydroxytoluene (BHT), propyl gallate (PG), and tert-butylhydroquinone (TBHQ) (Velioglu et al., 1998). However, they are suspected of being responsible for liver damage and carcinogenesis in laboratory animals. Naturally occurring substances in higher plants have antioxidant activity that has long been recognized. Thus, the interest in natural antioxidants has increased considerably. In this respect, we screened some in vitro antioxidant activities of Vetiveria zizanioides root extract for the possible discovery of safer and efficacious plant antioxidant agent(s).

To the best of our knowledge and the literature search, it was revealed that only a few scientific studies has been undertaken to evaluate $V$. zizanioides to its therapeutic potential in phytomedicine or its value for the isolation of active chemical constituents. Therefore the current study was designed and undertaken to screen $V$. zizanioides to confirm and provide scientific basis for its use in traditional system of medicines and also to explore some new biological and pharmacological activities of this plant.

\section{Materials and Methods}

\section{Preparation of the extract}

Fresh roots of $V$. zizanioides were collected and dried in shade under room temperature, powdered mechanically and sieved through No. 22 mesh sieve. The finely powered roots were kept separately in an air tight container until the time of use. About $750 \mathrm{~g}$ of powder was soaked with 3 litres of ethanol for $12 \mathrm{~h}$ and then macerated at room temperature using a mechanical shaker for $4 \mathrm{~h}$. The extract was filtered off and the marc was again soaked and then further extracted for $4 \mathrm{~h}$ and filtered. The filtrates were then combined concentrated under reduced pressure and evaporated at $40^{\circ} \mathrm{C}$. The percentage yield of the ethanolic extract of $V$.zizanioides (EEVZ) was found to be $8.7 \% \mathrm{w} / \mathrm{v}$.

\section{Drugs and chemicals}

Ascorbic acid, 2, 2 diphenhy-1-picryl hydrazyl hydrate (DPPH), ammonium molybdate, beta carotene, xanthine oxidase were purchased from Himedia, Mumbai. Hypoxanthine, 2deoxy-2-ribose, quercetin, pyrocatechol, butyl hydroxy toluene (BHT) were procured from SRL, Mumbai. Thiobarbituric acid, tricholoacetic acid, Folin ciocalteau reagents were purchased from SD Fine ltd., Mumbai. All other chemicals employed in the study were of analytical grade which was purchased from respective suppliers.

\section{Phytochemical screening}

Preliminary phytochemical screening of the powdered leaves was performed for the presence of alkaloids, flavonoids, tannins, phenols, terpenoids and saponins.

\section{Reducing power ability}

Reducing power ability was measured by mixing the EEVZ (50-800 $\mu \mathrm{g})$ in $1 \mathrm{ml}$ of distilled water to $2.5 \mathrm{ml}$ of phosphate buffer $(0.2 \mathrm{M}, \mathrm{pH} 6.6)$ and $2.5 \mathrm{ml}$ of $1 \%$ potassium ferric cyanide and then the mixture was centrifuged for $10 \mathrm{~min}$ at $3000 \mathrm{rpm}$, about $2.5 \mathrm{ml}$ from the upper part was diluted with $2.5 \mathrm{ml}$ water and shaken with $0.5 \mathrm{ml}$ fresh $0.1 \%$ ferric chloride. The absorbance was measured at $700 \mathrm{~nm}$ using UV-spectrophotometer. Increased absorbance of the reaction mixture indicates increased reducing power. All experiments 
were done in triplicate using butyl hydroxy toluene (BHT) as positive control (Yildirim et al., 2001).

\section{Superoxide radical scavenging assay (NBT reduction assay)}

A final volume of $3 \mathrm{ml}$ per tube was prepared as a reaction mixture with $1.4 \mathrm{ml}$ of $50 \mathrm{mM}$ $\mathrm{KH}_{2} \mathrm{PO}_{4}-\mathrm{KOH}$, pH 7.4 containing $1 \mathrm{~mm}$ EDTA, $0.5 \mathrm{ml}$ of $100 \mu \mathrm{M}$ hypoxanthine, $0.5 \mathrm{ml}$ of 100 $\mu \mathrm{M}$ NBT. The reaction was started by adding 0.066 units per tube of xanthine oxidase freshly diluted in $100 \mu \mathrm{l}$ of phosphate buffer and $0.5 \mathrm{ml}$ of the test extract in saline. The xanthine oxidase was added last. The basis of spectrophotometric determinations of absorbance was the subsequent rate of NBT reduction at $560 \mathrm{~nm}$. The standard employed was ascorbic acid. The results were expressed as the percentage inhibition of NBT reduction rate with respect to the reaction mixture without the test compound (saline only) (Guzman et al., 2001).

\section{Deoxyribose degradation assay (Hydroxyl radical scavenging activity)}

Hydroxyl radicals were decomposed by EEVG, which was determined by the assay of malondialdehyde chromogen formation due to 2-deoxy 2-ribose degradation. The assay mixture contained in a final volume of $1 \mathrm{ml}$ : $100 \mu \mathrm{l}$ of $28 \mathrm{mM}$ 2-deoxy 2-ribose dissolved in phosphate buffer, $\mathrm{pH} 7.4,500 \mu \mathrm{l}$ of the EEVZ of various concentrations (5-80 $\mu \mathrm{g})$ in buffer, 200 micro 1 of $20 \mathrm{mM}$ ferric chloride $(1: 1 \mathrm{v} \backslash \mathrm{v})$ and $1.04 \mu \mathrm{M}$ EDTA and $100 \mu \mathrm{l}$ of $1.0 \mu \mathrm{M}$ hydrogen peroide and $100 \mu \mathrm{l}$ of $1.0 \mu \mathrm{M}$ ascorbic acid. After incubation of the test sample at $37^{\circ} \mathrm{C}$ for $1 \mathrm{~h}$ the extent of free radical damage imposed on the substrate deoxyribose was measured using thiobarbituric acid (TBA) test. For the TBA test, about $1 \mathrm{ml}$ of thiobarbituric acid in $50 \mathrm{mM}$ sodium hydroxide and $1 \mathrm{ml}$ of $2.8 \% \mathrm{~W} / \mathrm{V}$ trichloroacetic acid was added to the test tubes and heated at $100^{\circ} \mathrm{C}$ for $20 \mathrm{~min}$. after cooling absorbance was measured at 532 $\mathrm{nm}$ against a blank containing deoxyribose and buffer only. Percentage inhibition of deoxyribose degradation was calculated. Quercetin was used as standard (Gomes et al., 2001).

\section{Estimation of total antioxidant capacity}

Total soluble phenolics in the extract were determined with Folin-Ciocalteu reagent according to the method of Gulcin et al. (2004). Pyrocatechol is used as the standard and expressed as $\mu \mathrm{g}$ pyrocatechol equivalents (PCE). One millilitre $(1000 \mu \mathrm{g} / \mathrm{ml})$ of extract solution in a test tube was added to $0.2 \mathrm{ml}$ of Folin Ciocalteu reagent (1:2 in distilled water) and after $20 \mathrm{~min}, 2.0 \mathrm{ml}$ of purified water and $1.0 \mathrm{ml}$ of sodium carbonate (15\%) are added. Allowed to react for $30 \mathrm{~min}$ and then absorbance was measured at $765 \mathrm{~nm}$. The concentration of total phenolic component in the EEVZ was determined as microgram of pyrocatechol equivalent/mg (Gulcin et al., 2004).

To determine the total flavonoid, about $1 \mathrm{mg}$ samples were added in $1 \mathrm{ml}$ of $80 \%$ ethanol. An aliquot of $0.5 \mathrm{ml}$ was added to test tubes containing $0.1 \mathrm{ml}$ of $10 \%$ aluminum nitrate, $0.1 \mathrm{ml}$ of $1 \mathrm{M}$ potassium acetate, and $4.3 \mathrm{ml}$ of $80 \%$ ethanol. The absorbance of the supernatant was measured at $415 \mathrm{~nm}$ after $40 \mathrm{~min}$ at room temperature. Quercetin was the standard used to calculate total flavonoid concentration.

The total antioxidant capacity of $V$. zizanioides was evaluated by the method of Asokkumar et al. (2008). The total antioxidant capacity of the extract of $V$. zizanioides was determined with phosphomolybdenum using $\alpha$-tocopherol as the standard. An aliquot of $1.0 \mathrm{ml}$ of extract $(1000 \mu \mathrm{g})$ solution is combined with $1.0 \mathrm{ml}$ of reagent $(0.6 \mathrm{M}$ sulphuric acid, $28 \mu \mathrm{M}$ sodium phosphate and $4 \mu \mathrm{M}$ ammonium molybdate). The tubes were capped and 
incubated in a boiling water bath at $95^{\circ} \mathrm{C}$ for $90 \mathrm{~min}$. after the samples had cooled to room temperature, the absorbance of the aqueous solution of each were measured at $695 \mathrm{~nm}$ in UV spectrophotometer. The blank solution contained $1.0 \mathrm{ml}$ of reagent solution and the appropriate volume of the same solvent used for the sample and it was incubated under same conditions as the rest of the samples. The total antioxidant capacity was expressed as equivalents of $\alpha$-tocopherol (Asokumar et al., 2008).

The concentration $(\mu / \mathrm{ml})$ of the extract required to scavenge the radicals was calculated by using the percentage scavenging activities at five different concentrations of the extract. Percentage inhibition (I \%) was calculated using the formula:

$$
\mathrm{I} \%=\underline{(\mathrm{Ac}-\mathrm{As})} \times 100
$$

Ac

Where Ac is the absorbance of the control and As is the absorbance of the sample.

\section{Results}

Preliminary phytochemical screening of the hydroethanolic extract of $V$. zizanioides (EEVZ) revealed the presence of alkaloids, flavonoids, tannins, phenols, saponins and triterpenoids. Table 1 shows the reductive capabilities of EEVZ when compared to the standard butylated hydroxyl toluene (BHT). The increase in absorbance of the reaction mixture containing the extract showed increased reducing power with increase in concentration. The reducing power increased significantly $(P<0.01)$ with increasing concentration of the extract. However, the activity of the extract $(0.8451 \pm 0.001)$ was lower than the standard (1.0794 \pm 0.010$)$. The EEVZ was found to be a scavenger of superoxide anion generated in xanthine oxidase-NBT systems.

Table 1: Reducing power ability

\begin{tabular}{lccl}
\hline Group & Concentration in $\boldsymbol{\mu g} / \mathbf{m l}$ & Absorbance at & $\mathbf{7 0 0} \mathbf{~ n m}$ \\
\hline Control & 50 & $0.1192 \pm 0.001$ & \\
EEVZ & 100 & $0.1956 \pm 0.003$ & \\
& 200 & $0.2871 \pm 0.008$ \\
& 400 & $0.4217 \pm 0.004$ & \\
Butyl hydroxyl toluene & 800 & $0.8451 \pm 0.001$ & \\
& 50 & $0.2037 \pm 0.005$ & \\
& 100 & $0.3283 \pm 0.001$ \\
& 200 & $0.4747 \pm 0.003$ \\
\\
400 & $0.8566 \pm 0.001$ & \\
& 800 & $1.0794 \pm 0.010$ & \\
\hline
\end{tabular}

Values are mean S. E. M. $(\mathrm{n}=3), \mathrm{p}<0.001$ when compared with control.

The extract showed significant $(P<0.001)$ superoxide inhibiting activity a concentrations ranging from $25-400 \mu \mathrm{g} / \mathrm{ml}$. The $\mathrm{IC}_{50}$ of the EEVZ was found to be $130.36 \pm 6.13 \mu \mathrm{g} / \mathrm{ml}$ whereas the $\mathrm{IC}_{50}$ of the standard ascorbic acid is $100.33 \pm 2.61 \mu \mathrm{g} / \mathrm{ml}$. The degradation of deoxyribose by $\mathrm{Fe}^{3+}$ - ascorbate-EDTA- $\mathrm{H}_{2} \mathrm{O}_{2}$ system was markedly decreased by EEVZ indicating the significant $(P<0.001)$ hydroxyl radical scavenging activity. The $50 \%$ inhibitory concentration of quercetin was $15.5 \pm 3.42 \mu \mathrm{g} / \mathrm{ml}$. The amount of total phenolic content in the extract correlated with the antioxidant activity. About $42 \mu$ pyrocatechol equivalent of phenols was detected in $1 \mathrm{mg}$ of EEVZ. 
Table 2: Superoxide radical scavenging activity

\begin{tabular}{|c|c|c|c|c|}
\hline Group & $\begin{array}{c}\text { Concentration } \\
\mu \mathrm{g} / \mathrm{ml}\end{array}$ & $\begin{array}{l}\text { Absorbance at } \\
700 \mathrm{~nm}\end{array}$ & $\%$ inhibition & $\begin{array}{l}\mathrm{IC}_{50} \\
\mu \mathrm{g} / \mathrm{ml}\end{array}$ \\
\hline Control & & 1.140 & & \\
\hline \multirow[t]{5}{*}{ EEVZ } & 25 & $0.919 \pm 0.002$ & $19.50 \pm 0.21$ & \\
\hline & 50 & $0.721 \pm 0.004$ & $36.75 \pm 0.28$ & \\
\hline & 100 & $0.543 \pm 0.022$ & $52.36 \pm 1.94$ & $130.36 \pm 6.13$ \\
\hline & 200 & $0.377 \pm 0.001$ & $66.89 \pm 0.15$ & \\
\hline & 400 & $0.245 \pm 0.002$ & $78.50 \pm 0.23$ & \\
\hline \multirow[t]{5}{*}{ Ascorbic acid } & 25 & $0.910 \pm 0.006$ & $21.70 \pm 0.57$ & \\
\hline & 50 & $0.790 \pm 0.004$ & $30.64 \pm 0.43$ & \\
\hline & 100 & $0.654 \pm 0.023$ & $42.59 \pm 1.05$ & $100.33 \pm 2.61$ \\
\hline & 200 & $0.417 \pm 0.003$ & $63.41 \pm 0.26$ & \\
\hline & 400 & $0.215 \pm 0.002$ & $81.13 \pm 0.25$ & \\
\hline
\end{tabular}

Values are mean S. E. M. ( $\mathrm{n}=3), P<0.001$ when compared with control.

The results of total flavonoid content of EEVZ are shown in Table 4. The total flavonoid content of EEVZ was $50 \mu \mathrm{g}$ implying that EEVZ extract contains a high quantity of flavonoids. In the measurement of quantitative antioxidant capacity, about $12.5 \mu$ tocopherol/mg equivalent of phenols was detected in $1 \mathrm{mg}$ of EEVZ.

Table 3: Deoxyribose degradation assay

\begin{tabular}{|c|c|c|c|c|}
\hline Group & $\begin{array}{l}\text { Concentration } \\
\mu \mathrm{g} / \mathrm{ml}\end{array}$ & $\begin{array}{l}\text { Absorbance at } \\
700 \mathrm{~nm}\end{array}$ & $\%$ inhibition & $\mathrm{IC}_{50} \mu \mathrm{g} / \mathrm{m}$ \\
\hline \multirow[t]{6}{*}{ Control } & & 0.542 & & \\
\hline & 5 & $0.474 \pm 0.002$ & $12.42 \pm 0.37$ & \\
\hline & 10 & $0.443 \pm 0.001$ & $18.21 \pm 0.33$ & \\
\hline & 20 & $0.331 \pm 0.016$ & $38.87 \pm 1.90$ & $39.5 \pm 2.5$ \\
\hline & 40 & $0.264 \pm 0.001$ & $51.21 \pm 0.32$ & \\
\hline & 80 & $0.152 \pm 0.001$ & $71.87 \pm 0.23$ & \\
\hline \multirow[t]{5}{*}{ Quercetin } & 5 & $0.424 \pm 0.004$ & $21.64 \pm 0.86$ & \\
\hline & 10 & $0.346 \pm 0.001$ & $33.37 \pm 0.31$ & \\
\hline & 20 & $0.213 \pm 0.002$ & $60.17 \pm 0.81$ & $15.5 \pm 3.42$ \\
\hline & 40 & $0.124 \pm 0.002$ & $77.04 \pm 0.43$ & \\
\hline & 80 & $0.071 \pm 0.002$ & $86.78 \pm 0.43$ & \\
\hline
\end{tabular}

Values are mean S. E. M. (n=3), $<<0.001$ when compared with control.

Table 4: Total antioxidant capacity

Phosphomolybdenum method $(\mu \quad \alpha-$
$\begin{aligned} & \text { tocopherol/mg) } \\ & \text { Total phenolic content }(\mu \mathrm{g} \quad \text { pyrocatechol }\end{aligned}$
$\begin{aligned} & \text { equivalent) } \\ & \text { Total flavonoid content }(\mu \mathrm{g} \quad \text { quercetin } \\ & \text { equivalent/mg) }\end{aligned}$

\section{Discussion}

The reducing capability of the EEVZ was compared with the standard BHT. For the measurements of the reductive ability, we investigated the $\mathrm{Fe}^{3+}-\mathrm{Fe}^{2+}$ transformation in the presence of the EEVZ. The reducing capacity of a compound also serves as a significant 
indicator of its potential antioxidant capacity (Devi et al., 2008). However, the antioxidant capacity of antioxidants may have been attributed to various mechanisms, among which are the prevention of chain initiation, binding of transtition metal ion catalysts, decomposition of peroxides, prevention of continued hydrogen abstraction, reductive capacity and radical scavenging antioxidant activity (Gulcin et al., 2003). The presence of reductants (antioxidants) in the EEVZ causes the reduction of $\mathrm{Fe}^{3+}$ (ferric cyanide complex) to $\mathrm{Fe}^{2+}$ (ferrous form). The reducing power of the EEVZ increased with increasing concentration. In this study, yellow colour of the test solution changed to various shades of green and blue depending upon the reducing power of the extract.

Superoxide anions were generated in vitro enzymatically by hypoxanthine/xanthine oxidase system that reduces NBT and forms a blue coloured chromophore, formazone that can be measured at $560 \mathrm{~nm}$. Superoxide radicals generated in vitro by the system was determined by NBT photoreduction method. The decrease in absorbance at 560nm with antioxidants thus indicates the consumption of superoxide anion in the reaction mixture. Superoxide radical was converted by superoxidedismutase (SOD) to hydrogen peroxide, which subsequently can produce extremely reactive hydroxyl radicals in the presence of transition metal ions such as iron and copper or by UV photolysis. Determination of the mean rate of increase in absorbance over a 1 minute period provided a measure of the extent to which the EEVZ capable of inhibiting NBT reduction by the superoxide anion radical and thus superoxide scavenging activity.

Hydroxyl radicals are reactive biological molecules and their scavenging property may provide an important therapeutic approach against oxidative stress induced ailments. It is well established in the absence of EDTA, $\mathrm{Fe}^{3+}$ directly bind with deoxyribose sugar and causes its site specific degradation due to hydroxyl radicals which are found immediately at the vicinity of the ions binding site. Hydroxyl radicals are the most reactive radicals which are produced via the Fenton's reaction in living system. Hydroxyl radicals scavenging activity was quantified by measuring the inhibition of the degradation of the deoxyribose by free radicals (Guzman et al., 2001). Deoxyribose levels were determined by reaction with thiobarbituric acid.

Phenolics are widely distributed and are found in large quantity in the plant kingdom. They have been shown to the multiple biological functions including antioxidant (Hsu et al., 2006). According to the recent report, the phenolic compounds may contribute directly to the antioxidative action. In addition, it was reported that phenolic compounds were associated with antioxidant activity and play an important role in stabilizing lipid peroxidation (Gulcin et al., 2004). Phenolic compounds appeared to be responsible for the antioxidant activity of EEVZ. Folin - Ciocalteu method and aluminium chloride coloration are currently used to determine the total phenolic and flavonoid contents as they are important in various food materials. Phenols are very important constituents because of their scavenging ability due to their hydroxyl group. The chemical composition of plants indicates the presence of phenolic compounds which are known to possess antioxidant activities.

Flavonoids are a group of polyphenolic compounds, which exhibit several biological effects such as anti-inflammatory, antihepatotoxic, antiulcer, antiallergic, antiviral, anticarcinogenic and antioxidant properties. The important effect of flavonoids is the scavenging of oxygen-derived free radicals (Umamaheswari et al., 2009). The total flavonoid content in the extract was expressed as $\mu \mathrm{g}$ quercetin equivalent per mg. The EEVZ showed high flavonoid content which has contributed directly to the antioxidant activity by neutralising the free radicals. 
The phosphomolybdenum method was used to investigate the total antioxidant activity of the extract. The quantitative antioxidant capacity of EEVZ was measured spectrophotometrically through the phosphomolybdenum method which is based on the reduction of Mo (VI) to Mo (V) by the sample analyte and the subsequent formation of green phosphate/Mo (V) complex with a maximum absorption at $695 \mathrm{~nm}$ (Asokkumar et al., 2008)

Antioxidants derived from fruits, vegetables, spices and cereals are very effective and have reduced interference with the body's ability to use free radicals constructively. Natural antioxidants mainly come from plants in the form of phenolic compounds (flavonoids, phenolic acids and alcohols, stilbenes, tocopherols, tocotrienols) ascorbic acid and carotenoids. The quest for natural antioxidants for dietary, cosmetic and pharmaceutical uses has become a major industrial and scientific research challenge over the last two decades. Efforts to gain extensive knowledge regarding the power of antioxidants from plants and to tap their potential are therefore on the increase (Ali et al., 2008).

It can be concluded that therapeutic claims on EEVZ used as traditional plant have been supported by the results which show positive activity against free radicals. Further isolation of bioactive constituents in the extract would help to ascertain its potency and safety, to provide leads and candidates of antioxidants for dietary, cosmetic and pharmaceutical uses.

Received 17 November 2009

Revised 9 February 2010

Accepted 10 February 2010

\section{References}

Ajith, T.A. \& Janardhanan, K.K. (2002) Antioxidant and antihepatotoxic activities of Phellinus rimosus (Berk) Pilat. Journal of Ethnopharmacology 81, 387-391.

Ali, S.S., Kasoju, N., Luthra, A., Singh, A., Sharanabasava, H., Sahu, A., Bora, U. (2008) Indian medicinal herbs as sources of antioxidants. Food Research International 41, 1-15.

Amarowicz, R., Pegg, R.B., Moghaddam, P.R., Barl, B. \& Weil, J.A. (2004) Free-radical scavenging capacity and antioxidant activity of selected plant species from the Canadian prairies. Food Chemistry 84, 551-562.

Asokkumar, K., UmaMaheswari, M., Sivashanmugam, A.T., Subhadradevi, V., Subhasini, N. \& Ravi, T.K. (2008) Antioxidant activities of Erythrina stricta Roxb. Using various in vitro and ex vivo models. Oriental Pharmacy and Experimental Medicine 8, 266-278.

Gomes, A.J., Lunardi, C.N., Gonzalez, S. \& Tedesco, A.C. (2001) The antioxidant action of Polypodium leucotomos extract and kojic acid: reactions with reactive oxygen species. Brazilian Journal of Medical and Biological Research 34, 1487-1494.

Gulcin, I., Buyukokuroglu, M., Oktay, M. \& Kufreviolu, I. (2003) Antioxidant and analgesic activities of turpentine of Pinus nigra Arn. subsp. pallsiana (Lamb.) Holmboe. Journal of Ethnopharmacology 86, 51-58.

Gulcin, I., Kufrevioglu, O.I., Oktay, M., Buyukokuroglu, M.E. (2004) Antioxidant, antimicrobial, antiulcer and analgesic activities of nettle (Urtica dioica L.). Journal of Ethnopharmacology 90, 205-215.

Guzman, S.A., Gato, A. \& Calleja, J.M. (2001) Anti inflammatory, analgesic and free radical scavenging activities of the marine microalgae Chlorella stigmatophora and Phaeodactylum tricornutum. Phytotheraphy Research 15, 224-230. 
Hsu, C.Y. (2006) Antioxidant activity of extract from Polygonum aviculare L. Biological Research 39, 281-288.

Kang, D.G., Yun, C.K. \& Lee, H.S. (2003) Screening and comparison of antioxidant activity of solvent extracts of herbal medicines used in Korea. Journal of Ethnopharmacology 87, 231236.

Roome, T., Dar, A., Ali, S., Naqvi, S. \& Choudhary, M.I. (2008) A study on antioxidant, free radical scavenging, anti-inflammatory and hepatoprotective actions of Aegiceras corniculatum (stem) extracts. Journal of Ethnopharmacology 118, 514-521.

Umamaheswari, M., Asokkumar, K., Sudalaivelmurugiah, M., Sivashanmugam, A.T. \& Subhadradevi, V. (2009) Hypouricaemic and antioxidant activities of the fractions of Vitex negudo L. leaf extract. Phytopharmacology and Therapeutic Values 23, 59-70.

Velioglu, Y.S., Mazza, G., Gao, L. \& Oomah B.D. (1998) Antioxidant activity and total phenolics in selected fruits, vegetables, and grain products. Journal of Agricultural and Food Chemistry 46, 4113-4117.

Yildirim, A., Oktay, M. \& Bulaloulu, V. (2001) The antioxidant activity of the leaves of Cydonia vulgaris. Turkesh Journal of Medical Sciences 31, 23-27. 